\title{
DISCURSO PRONUNCLADO POR EL RECTOR DE LA UNIVERSIDAD DE CHILE EN EL ANIVERSARIO SOLEMNE DE 29 DE OCTUBRE DE 1848
}

\author{
Andrés Bello \\ SANTIAGO: IMPRENTA CHILENA, 1848. \\ (Texto completo)
}




\section{EXMO, SEÑOR PATRONO. SEÑORES.}

Cumplo con el deber que me impone el Reglamento de Consejo de la Universidad en su artículo 24. Conformándome a él, dirijiré vuestra atención a cuatro puntos: el estado actual de la instrucción pública: la enumeración de las mejoras introducidas en esta ramo, de sus resultados, i de los obstáculos que las hayan contrariado: un resumen de los acontecimientos que tengan relación inmediata con la instrucción pública; i una noticia de los miembros de la Universidad que han fallecido i que se hubieren distinguido por su zelo a favor del mismo objeto. Procuraré ser breve, i llenar, en cuanto me fuere posible, estas indicaciones.

Las tres primeras tienen tal conexión entre sí, que en beneficio de la brevedad i de la claridad misma de esta exposición, me parece conveniente no separarlas.

Respecto de la primera es poco lo que tengo que añadir al luminoso cuadro presentado a las Cámaras i al público por el Señor Ministro del ramo, Vice-patrono de la Universidad, en su Memoria de 11 de setiembre de este año. Propiciando por la instrucción primaria, es triste el paralelo de nuestra situación presente con la de otras naciones civilizadas; pues adoptando por base el total de los individuos que la reciben en toda la extensión de la República, según el estado general que acompaña a la Memoria citada; aumentándolo con la cuota correspondiente a la provincia de Chiloé, conforme a la noticia sumamente incompleta que existe en la secretaria de la Facultad de Humanidades; agregando conjeturalmente las cuotas de los departamentos de la provincia de Concepción que no pudieron comprenderse en aquel estado; i tomando en cuenta la inevitable deficiencia de los datos respecto de las otras secciones i de la provincia misma de Santiago, por considerable número de escuelas diminutivas, que se escapan a la observación, i de los individuos de ambos sexos que aprenden en sus casas, creo que podremos valuar el número de las personas a quienes se suministra el primer jermen de cultura mental, en uno por cada cuarenta i cinco habitantes; de que se deduce que se extiende, apenas, a la sexta parte de los que son llamados a recibirlo.

Es preciso reconocer que de todos los países que gozan de una civilización más o menos adelantada, ninguna presenta para la difusión de la enseñanza primaria las dificultades que Chile. En muchos de nuestros campos la población no forma vecindarios compactos, de tal cual importancia, como las aldeas i pueblos menores de Europa i de otros países de América; el viajero busca muchas veces en vano la 
apariencia de esos pequeños grupos de familias; i donde esperaba encontrar uno de ellos, lo que se le ofrece a la vista es un espacio extenso en que se levanta a largos derechos esparcidas habitaciones, que apenas comunican entre sí. De los que viven de este modo, ¿Cuántos son los que pueden enviar sus hijos a una escuela, que, por precisión, está situada a gran distancia de la mayoría? Los que se aprovechan del beneficio de la instrucción primaria, con que el Estado i las municipalidades les brindan, no guardan proporción ni con el número de las escuelas, ni con el costo invertido en ellas. Las mismas familias que, concentradas en una villa, pudieran dar 30 o 40 educandos, apenas contribuyen con una pequeña fracción de este número. Aun las que residen a moderada distancia, para proporcionar este bien a los niños tendrían que someterse a una privación casi completa del auxilio no insignificante que desde la primera edad pueden estos prestarles para sus diarios trabajos i para los menesteres domésticos. Así es que la mayor parte resiste a enviarlos, o solamente los dejan ir en la estación del año en que les es menos necesaria su ayuda. No solo es pues limitada la concurrencia a las escuelas, sino a menudo interrumpida; i de este modo la semilla preciosa que el Estado esparce a no pequeña costa sobre los campos de la República, se puede decir sin exajeración que no rinde la mitad del fruto que debiera.

Si queremos formar alguna idea de la cuota que cabe a cada provincia en esta distribución de la primera enseñanza, hallaremos una desigualdad notable, que no siempre es fácil explicar por las circunstancias locales i por la más o menos cultura de los pueblos. ¿Quién creería encontrar en el grado superior de esta escala a la provincia de Chiloé? A la verdad no tenemos acerca de ella datos medianamente completos; pero podemos computar en 26000 almas la población de los departamentos de Quinchaco, Calbuco, Dalcahue i Chonchi, juzgando por el censo de 1843, i a lo menos en 1500 el número de niños que frecuentan las escuelas, según los estados que he tenido a la vista; de que se distribuye allí la educación rudimental a uno de cada 17 individuos, cuando el término medio de toda la República es uno entre 45. Valparaíso, Santiago, Valdivia, Atacama i Talca exceden también al término medio i componen la parte más iluminada del territorio chileno. En la provincia de Valparaíso, que ocupa el segundo lugar, la cuota es 1 por 28; en la de Santiago 1 por 33; en la de Valdivia 1 por 38; en la de Atacama 1 por 40; en la de Talca 1 por 43; en la de Coquimbo 1 por 50; en la de Aconcagua 1 por 60; en la de Nuble 1 por 67; en la de Concepción (con la incertidumbre que nace de lo incompleto de las noticias) 1 por 75; en la de Maule 1 por 96; i en la de Colchagua, colocada en la última línea, i a bastante distancia de las otras, 1 por 450. Yo no pretendo presentar estos guarismos sino como meras aproximaciones, pero creo que no se aleja mucho de la realidad. (a) 
El departamento en que está más difundido la instrucción primaria es el de Valparaíso, donde cada 12 individuos de toda edad i sexo, va uno a la escuela. En el de Calbuco de cada 14 individuos, i en el de Santiago de cada 27, va uno.

Calculando la proporción de los sexos en la asistencia a las escuelas no tendremos tampoco motivo de felicitarnos. Como al total de niñas que participan de la enseñanza primaria, según aparece en el Estado adjunto a la Memoria ministerial, no sería razonable hacer iguales agregaciones que al de niños, la proporción de las primeras es necesariamente algo menor de lo que en él presenta, i se puede conjeturar con alguna verosimilitud que de cada seis niños que van a la escuela, los cinco pertenecen a nuestro sexo.

Si pasamos ahora a la apreciación de la enseñanza que se da en las escuelas a los que no sufren los inconvenientes que he tenido el honor de indicaros, o pueden con algún esfuerzo vencerlos, encontraremos que en ningún punto de la República se le ha dado todavía toda la extensión que sería de desear, i que a solo podría llegar gradualmente en una serie de años. Hai con todo localidades en que se examina con más o ménos celeridad a este apetecible desarrollo. A la lectura, escritura i rezo, que forman todo el pábulo mental que se da en varias escuelas a la niñez, i aun ese de un modo defectuoso, hai muchas que añaden el catecismo i principios de aritmética; crece el número de aquellas en que se desenvuelve algo más el cálculo i se dan nociones de gramática castellana; en las escuelas de niños ocupan más o menos lugar los ejercicios i habilidades propias del sexo.

La falta de idoneidad de los profesores que en muchas partes retardan el progreso, es un obstáculo que solo puede remediarse lentamente por el número de jóvenes que reciben una instrucción adecuada i hacen su aprendizaje de pedagojía en la Normal, o que se forman en las mejores escuelas de las provincias. Desgraciadamente no puede contarse con todos ellos; porque en un país donde tantas ocupaciones lucrativas, solo una decidida vocación a las tareas ingratas i deslucidas de la enseñanza más elemental, retendrá en ella a las intelijencias que hayan recibido cierto cultivo, i poco podrían esperarse de las medidas que se empleasen para hacerlas permanecer en un ejercicio de tan poco lucro i brillo, contrariando sus inclinaciones i sus miras de mejor fortuna. A la verdad, no se puede decir que se desperdicie así del todo la simiente preciosa, creada en aquellos planteles; porque en todas las ocupaciones sociales será útil hasta cierto punto la adquisición de personas preparadas en ellos; pero este capital de conocimientos se desvía así del empleo a que lo ha destinado la Nación, i en que pudiera producir más ventajas; porque el más provechoso, como el más necesario de todos es, incontestablemente, el que difunde las nociones rudimentales en que termino la barbarie i aparece el primer albor de civilización. 
La Facultad de Humanidades se ha consagrado con un zelo constante al desempeño del encargo que sobre la instrucción primaria lo encomendó la lei orgánica de la Universidad. Ella ha mirado con atención preferente la Escuela Normal, a la que el digno Decano hace espontáneamente, o en comisiones de la Facultad, frecuentes visitas de inspección. Tengo la complacencia de decir que en ellas ha visto mejorarse gradualmente el rejimen del establecimiento, merced al interés que ha tomado en ello nuestro Gobierno, i a las luces i la asidua contracción del benemérito director (b). El Plan de estudios ha sido poco hace revisado por la Facultad i el Consejo, i aprobado por el Gobierno; él abraza en el día, además de la lectura, escritura i aritmética, la gramática castellana, el dibujo lineal, la cosmografía, la jeografia física i descriptiva, el dogma i moral cristiano, los fundamentos de la fe, la historia sagrada i profana, i el canto. El local es ya medianamente cómodo, i lo será de todo punto, cuando esté concluido el edificio, como lo veremos mui pronto. La institución del internado ha correspondido a lo que se esperaba de ella. Una disciplina severa garantiza la normalidad de los alumnos. En una escuela sucursal se ensaya prácticamente la pedagojia; i la vecindad de la Quinta Normal, ha parecido un medio oportuno de suministrar a los futuros preceptores algunos conocimientos elementales en la teoría i en la práctica de la agricultura, que llevados después a las provincias, no dejaran de influir en el proceso de esta industria bienhechora, que tanto importa a Chile. En fin, a esta extensa i variada instrucción, que ocupa tres años se agregaran nociones prácticas en agrimensura, vacunación, idioma francés i algún otro estudio, a juicio del Director; dedicando a ellos los alumnos, especialmente los más adelantados, el tiempo vacante que sus ocupaciones ordinarias les dejaren.

El Consejo de la Universidad, por su parte, se ha ocupado sin cesar en el examen de los estados que periódicamente se le remiten de las provincias i departamentos; i aunque ciertamente es grande el número de las secciones en que se ha faltado a este deber, hai departamentos $i$ aun provincias enteras en que las Juntas $i$ las inspecciones lo cumplen con laudable regularidad. Son frecuentes las demandas de auxilios indispensables para el servicio de las escuelas; i el Consejo trasmite estas peticiones al Gobierno, que rara vez deja de satisfacer a ellas con remesas tan abundantes como le es posible. Así ha desaparecido en alguna parte la práctica de poner en manos de los niños para sus primeras lecturas libros ininteligibles a su edad i tal vez perniciosos, sustituyéndose a ellos los que con este objeto han dado a la luz las prosas chilenas; de los cuales i de los otros que han parecido adaptables ha formado la Facultad una lista, que se ha circulado. Estos libros se distribuyen gracias a los alumnos indigentes, $i$ el resto se vende a un precio ínfimo, que se aplica a las otras necesidades de las escuelas. Se han dictado también providencias para mejorar el local de algunas demasiado estrecho, expuesto a la intemperie, o situado en pareja ménos a propósito por la escasez del vecindario. Se emplea el cuidado posible en 
la buena conducta en la asiduidad de los preceptores. I en suma nada omite el Gobierno para subvenir a las más imperiosas necesidades, ya fundando escuelas primarias donde más se siente su falta, ya proveyéndolas de los más indispensable, donde existen.

La Facultad de humanidades, no contenta con observar de cerca la Normal i dirijir sus progresos, ni con la inspección de las otras escuelas de Santiago, se ha dedicado a la revisión de textos, libros de lectura i programas. Algunos de estos libros han sido compuestos, traducidos o adaptados, a las escuelas de Chile por miembros de la Facultad, i entre ellos merece señalarse la Vida de Jesús-Cristo (c), no solo por la acertada elección, sino por la sencillez i pureza del lenguaje, requisito indispensable en todos los textos i sobre todo en las obritas que se destinan las primeras lecturas, pero que por desgracia no siempre se solicita con suficiente esmero. Debo mencionar también el Tratado de Pedagojia i el Libro de las Madres i Preceptoras (d), que tienen entre otras calidades recomendables la de la adaptación a Chile, el Compendio de la Historia de Chile (e) (...) social y bien escrita cartilla de aritmética, (...) ya en las mejores escuelas (f). Aun ha hecho más la Facultad ha extendido sus miras a la organizaciones de todo lo concerniente a la instrucción primaria en todo el territorio de la República. El producto de sus trabajos, preparados por uno de sus más zelozos i laboriosos miembros (g) ha sido el proyecto de lei propuesto últimamente, con lijeras modificaciones, a las Cámaras Legislativas por el patriótico Secretario de la misma (h). En él se ha procurado la más conveniente distribución de este beneficio a toda la población chilena, ampliando, graduando, mejorando la enseñanza, i haciendo del preceptorado una carrera honrosa, que atraiga competentes capacidades con dos nuevos i poderosos alicientes, la distinción i la esperanza. La Facultad no ha podido dejar de reconocer que el alma de todo sistema orgánico de enseñanza primaria es la frecuente inspección. Lo que actualmente existe, ejercidas por personas que cuando estén animadas del mejor espíritu, carecen, por la mayor parte, de otras cualidades no menos esenciales, pero que no sería justa exijir de ellas, no puede nunca ponerse en paralelo con la de visitadores idóneos, que se envíen periódicamente a las provincias. Se ha principado a ensayar este método con buen suceso. El público ha sido el resultado de la visita de Colchagua por un joven que ha manifestado especial vocación para la enseñanza primaria (i). Del patrocinio que nuestro Gobierno dispensa a la educación popular, me prometo que se continuará en el plan de inspección por visitas, cualquiera que sea la suerte que tenga bajo otros respectos el proyecto de la Facultad; i que se multiplicarán gradualmente los visitadores, hasta que puedan recorrerse cada año todas las escuelas de la República, i especialmente las que se sostienen con fondos fiscales o municipales. Combinando las dos especies de inspección, podríamos lisonjearnos de tener en breve un sistema 
de educación primaria más eficiente, que el que ahora consume con escaso fruto erogaciones cuantiosas.

Un Miembro de la Facultad de Humanidades, que ha hecho de la instrucción primaria un objeto especial de estudio, i a quien nuestro Gobierno dio el encargo de observar la organización desde ramo en las naciones más adelantadas de Europa i América, ha regresado, poco tiempo hace, i presentará en breve al Gobierno, a la Universidad i al público el fruto de sus laboriosas investigaciones. Creo justo decir, por la muestra que se ha dado de ellas a la Facultad de Humanidades en una de sus sesiones, presenciada por el señor Ministro de instrucción pública, i a que yo también tuve el honor de asistir, que Don Domingo Faustino Sarmiento ha hecho un acopio abundante de datos preciosos, de que pueden hacerse convenientes aplicaciones a nuestro país, con las modificaciones que las circunstancias requieran. Ninguna materia de las concernientes a la instrucción primaria, ha sido desatendida por el ilustrado viajero; i entre ellas la enumeración de los medios que se han empleado en otras naciones con el objeto de sufragar a los costos necesariamente considerables de una extensa instrucción primaria abierta a todas las clases i verdaderamente popular, que la parte a que se contrajo la lectura del voluminoso manuscrito, no es la de menos importancia para nosotros.

En vano pediriamos a la experiencia de otros pueblos un plan completo, adaptable a todo el territorio chileno, bajo los accidentes especiales que en gran parte lo caracteriza, i que ha tenido el honor de indicarnos. Pero concibo que en algunas de sus publicaciones, i tal vez en departamentos enteros, no sería difícil la adaptación, parcial a lo menos, de alguno de los sistemas que en Europa i los Estados Unidos de América han pasado por la parte del tiempo, acarreando resultados que han excedido a todas las esperanzas. Séame permitido añadir que en este, como en otros objetos, nada convendría menos que aspirar a esa severa uniformidad en que algunos cifran la perfección; i que someter a una misma norma (...) que ahondan de cuando es necesario para organizar un buen plan de instrucción primaria, i poblaciones que carecen de todo hasta del deseo de mejorarse, sería defraudar a las primeras de lo que tienen derecho a esperar, i perjudicar al mismo tiempo a las otras; a quienes Santiago, Valparaíso, Talca, Copiapó i otros pueblos de la República, bien organizados, presentarían modelos que imitar i elementos de que aprovecharse.

No podemos menos de unir nuestros votos a los del Señor Vice-patrono por el establecimiento de las Salas de Asilo, destinadas a instruir i moralizar la niñez en la porción más indigente de la sociedad, donde no tiene por regular otra estructura que el mal ejemplo i la vagancia.

Es imposible pintar con más vivos colores que lo ha hecho Su Señoría la importancia de las salas de asilo, i es fácil calcular los saludables efectos que producirán a la sociedad toda, disminuyendo el número de los delitos que alarman 
el hogar doméstico i forman uno de los más gravosos i desiguales impuestos sobre la propiedad. El clero, los vecinos acomodados, el lo sexo, aceptaran sin duda la filantrópica invitación de Su Señoría; i los datos recojidos por el Gobierno, a que el Señor Sarmiento añadirá instructivas noticias acopiadas en su viaje, facilitaran la planta de esta benéfica institución en los principales pueblos de la República.

Yo no puedo terminar este cuadro del estado i esperanzas de la educación primeria, sin ofrecer el debido reconocimiento a los relijiosos i religiosas de los Sagrados Corazones, que dedicados por su instituto a este caritativo ministerio, la dispensan gratis a gran número de niños de ambos sexos, además de contribuir a la educación colejial en establecimientos separados, con edificios competentes, construidos a su propia costa, i con un rejimen bien entendido, en que se consulta especialmente la moralidad de los alumnos. Ni sería justo pasar en silencio a la Cofradía del Santo Sepulcro, que zeloza de promover la enseñanza en las clases menos acomodadas de la sociedad, ha fundado una escuela gratuita de dibujo lineal, que cuenta tres años de existencia. El Sr. Decano de Humanidades, en los informes que sobre la materia ha dado el Consejo, elojia la facilidad i aun cultura con que se a producido los jóvenes artesanos en sus explicaciones orales, $i$ la rápida destreza de sus operaciones en la pizarra. Los exámenes de este año han sido particularmente admirados. Comprendieron, además de la teoría i practica del dibujo lineal, acciones de jeometria descriptiva, i rudimientos de arquitectónica. El mismo Sr. Decano, que presta especial atención a este interesante plantel, ha tributado las debidas alabanzas a la contracción i zelo de don Luis Prieto i Cruz, a su benevolencia con los artesanos, a su desinteresada dedicación, i a los sazonados frutos de inteligencia i moralidad con que ha visto coronar sus trabajos. El Supremo Gobierno ha hecho una pública demostración de reconocimiento al digno Profesor, i acordó además la compra de veinte $\mathrm{i}$ ocho de los mejores dibujos presentados a examen.

La enseñanza del dibujo lineal, según nos asegura el Sr. Ministro de Justicia, medra en algunas provincias, i será en breve restituida a su prosperidad anterior en el Instituto Nacional, mediante el restablecimiento de la esencion del servicio en las milicias, de que antes gozaban los alumnos. La escuela de Artes i Oficios se abrirá en breve. La Pintura i Escultura principiarán a cultivarse bajo la dirección de un sobresaliente artista extranjero, i ya se empieza a recoger algunos elementos para la formación de un gabinete.

Distinciones burocráticas a la modesta industria, a las artes liberales que suavizan las costumbres i elevan el alma, son, como lo ha observado nuestro digno VicePatrono el mejor estímulo para su fomento. Yo me complazco en mediar los elojios de su Señoría al ciudadano que conciba la idea de una distribución de premios de esta naturaleza en la gran fiesta de la Patria. ¡Honor al amigo del pueblo, al amigo de la humanidad, a que se debe la institución del aniversario de Caridad Cristianaj 
(j) ¡Honor al Gobierno que ha comprendido la importancia de esta institución, i ha querido solemnizar con su asistencia ;

La instrucción preparatoria i superior se nos presenta bajo un aspecto lisonjero, i en esta parte merece mucha más confianza la exactitud de sus datos. El total es de 3400 educandos, que es como uno en cada 350 habitantes; proporción que no debe parecer excesiva en un país en que el réjimen constitucional llama gran número de individuos al ejercicio de funciones importantes, no solo en las profesiones literarias, sino en la representación nacional, en el servicio de las municipalidades, de las oficinas públicas, i de la administración de justicia, i en que la clase de propietarios territoriales i de personas acomodadas es cada día proporcionalmente más numerosa. Corresponde a la Provincia de Santiago 51 centésimos, i a la capital 49; lo que tan poco parecerá desproporcionado, si se tiene presente que este último guarismo contiene casi en su totalidad la instrucción científica de la República i una parte también considerable de la instrucción colejial. La proporción en que esta se distribuye entre los diferentes sexos, no es siquiera la de 1 a 3 , pues de 100 personas que la reciben, apenas 30 son niñas; pero bajo este respecto hai una notable desigualdad entre las diferentes provincias. En las de Coquimbo, Valdivia i Chiloé no hai establecimientos para proporcionar este beneficio a las mujeres; en Concepción i Talca las educandas no llegan a la tercera parte del total; en Valparaíso pasa de la mitad; en Colchagua alcanzan a mas de 55 por 100, i en Maule hacen justamente un 70 por 100 . Santiago presenta a primera vista un resultado muy poco satisfactorio, pues las mujeres que reciben una instrucción superior a la de las escuelas no llegan a la cuarta parte del total de ambos sexos a que se suministra esa educación. Pero hay que notar: $1^{\circ}$ que en los colejios de varones de la capital una porción considerable de los alumnos no pertenecen a su vecindario, lo que al paso que extrajera la cuota de varones en la provincia de Santiago, la rebaja en las otras; i $2^{\circ}$ que en ciertas familias cuyo número crece continuamente, las niñas reciben el complemento de su educación al lado de sus padres. Podemos pues admitir con seguridad que la proporción de los sexos es algo más favorable a la mujer, de lo que aparece en los anteriores guarismos. Sin embargo, aun tomando en cuenta estas observaciones, el número de las mujeres a quienes se ofrece una instrucción superior a la ínfima de las escuelas es mucho menor de lo que debiera; i me parece una necesidad imperiosa aumentarlo. La proporción, según hemos visto, es mucho menor respecto de la enseñanza primaria, i en ella es también más urjente el remedio. A lo mejor ha confinado la naturaleza una misión sagrada la de influir al niño las primeras nociones, $\mathrm{i}$ lo que, es más, los primeros sentimientos de relijion i moral. Forman buenas esposas i buenas madres es proveer al primero de todos los objetos en el programa de la educación nacional. 
Relativamente a la instrucción colejial se me permitirá llamar vuestra atención a lo que me parece un vacío.

En los colejios de niñas se da a la mujer una instrucción general acomodada a todas las situaciones de la vida; más o menos completa, sin duda; pero no calculada como una preparación para otros estudios. No es así en la juventud de nuestro sexo. Generalmente hablando, la que entra en los colejios lleva puesta la mira en la adquisición de los conocimientos superiores, necesarios para el ejercicio de una profesión peculiar; la del foro en la mayor parte de los casos, la eclesiástica, medical o comercial, o la de agrimensores o injenieros, en otros.

Pero pocos, poquísimos frecuentan las aulas con el solo objeto de dar al entendimiento aquel cultivo indispensable de que en una sociedad adelantada no debe carecer ningún individuo que no pertenezca a las ínfimas clases.

Lo que suple en cierto modo esta falta es el gran número de los que habiéndose iniciado en los estudios preparatorios de una carrera literaria, la abandonan, i llevan a los destinos subalternos aquel caudal de luces que han podido adquirir en su infructuosa tentativa. ¿I de qué les sirve entonces el tiempo invertido en ciertos estudios que solo tienen valor como un medio para subir a otros de más elevación e importancia? ¿De qué les sirve, por ejemplo dos o tres años empleados en la adquisición del latín, que no los habilitan ni para entender siquiera este idioma?

Es evidente que igual tiempo i trabajo dedicados a objetos de general aplicación, hubieran sido de más provecho para ellos i para la sociedad entera. Si se considerase como indispensable a todos los que no vivan del trabajo mecánico esta instrucción general, sin la mira ulterior a una profesión literaria, no veríamos tan frecuentemente personas de otras clases, que no habiendo recibido más cultivo intelectual que el de las primeras letras, o habiendo dedicado tal vez a la instrucción colejial una parte considerable de la edad más preciosa, no pueden mostrarse decorosamente en el trato social, lo deslucen en cierto modo, y tampoco pueden ejercer como es debido los derechos del ciudadano, i los cargos a que son llamados en el servicio de las comunidades o con la administración inferior de justicia.

Por el orijen del mal no está tanto en la organización de los estudios colejiales, como en la general era la preocupación que solo ve en ellos el camino que conduce a los destinos profesionales. Poquísimos entran a neutros colejios sin esta aspiración a las carreras superiores. Se emprenden de una marcha en que es dado a pocos llegar al término apetecido; ¡el resultado forzoso es el desperdicio de mucho tiempo y trabajo, i la acumulación de un número desproporcionado de alumnos en ciertas clases que solo tienen una utilidad relativa, $i$ en que la excesiva concurrencia abruma al profesor i perjudica a la enseñanza ¿I de qué arbitrio puede echarse mano para minorar el mal? Si hubiese una separación completa entre la enseñanza propiamente preparatoria i la instrucción general de que hablamos; si se destinasen clases i cursos 
aparte para una i otra, es harto probable que los destinados a la segunda serian mirados con desdén, i que la juventud correría en tropel a los otros con el mismo empeño que ahora. Es el Instituto Nacional se ha dado el primer paso para llenar el vacío que os he señalado; pero en esta materia el resultado a que aspiramos solo puede ser la obra del tiempo. La superabundancia de aspirantes a los destinos forenses hará menos cuantioso sus emolumentos; i a medida que sea menor el aliciente i mayor el número de esperanzas frustradas en esta ardua carrera, serán más concurridas las otras, i más solicitadas por sí mismos los conocimientos de uso jeneral.

En los ramos de instrucción preparatoria i superior están a la vista de todas las mejoras i progresos de los últimos años. He tenido ocasión de apreciarlas en los exámenes del último año escolar. Las muestras dadas en la gramática del idioma nativo, en el francés, en el inglés, en la jeografía i cosmografía, en la historia sagrada i profana, en la literatura, en la filosofía, en las ciencias médicas, en el derecho, han dejado poco que desear. Debo notar como uno de los mejores síntomas de adelantamiento, el desarrollo que se ha dado al estudio de las lenguas castellanas i latina. El de las matemáticas había llegado antes de esta época a un punto de que no era fácil que subiese, i si los otros estudios han adelantado comparativamente más, consiste en el superior desenvolvimiento que de antemano había tenido el de matemáticas, i a que los otros no han llegado sino mucho más tarde. Pero en el estudio de las ciencias físicas es en el que encuentro más motivo de felicitación, por el impulso que les da actualmente un distinguido profesor, que a sus profundos conocimientos reúne aquella cualidad tan importante en el profesorado, el amor puro i desinteresado al saber. Este entusiasmo jeneroso (de que no faltan otros ejemplos en el Instituto Nacional?, comunicado a la mejor parte de los alumnos, es un don de mucho más precio que el de la enseñanza que se les dispensa; no solo porque lleva en sí la semilla de frutos adelantamientos, sino porque eleva i ennoblece las almas. Otra circunstancia que merece mencionarse de un modo especial, es la extensión con que hoy e estudian la historia i fundamentos de la Relijion. La enseñanza relijiosa es la materia a que el Consejo de la Universidad consagra una atención más detenida i constante en el examen de los estados e informes que sobre la instrucción primaria i colejial se le remiten periódicamente.

En esta lijera ojeada sobre el estado actual de la enseñanza preparatoria i superior, no debo omitir la importancia que se ha dado a las oposiciones, certámenes literarios o científicos en que los aspirantes a clases vacantes de provisión suprema ofrecen una muestra pública de sus talentos i aptitudes. Todos saben el interés que las últimas han excitado, i es fácil calcular el poderoso estímulo que dan a la parte más brillante de la juventud que cursa las altas clases, que es la que generalmente suministra candidatos al profesorado de inferiores. Las reglas prescritas por el Gobierno a las 
oposiciones, abren un teatro lucido a los estudios i garantizan la imparcialidad de los nombramientos. Creo, con todo, que es necesario variar la forma de las opciones, según las especialidades del ramo literario o científico sobre que recaen. En los que tienen aplicaciones manuales como la anatomía i la quizás laica, insutral, física, la manipulación, es una parte esencial. En los de literatura lo son la análisis i la composición como en los de lenguas la traducción extenuante del idioma extraño al nativo, i recíprocamente. No obstante más que en todos se sometiese los candidatos a la prueba de la interrogación por personas competentes, nombradas al efecto. Finalmente, no pueden tomarse demasiadas precauciones contra el peligro de que en los discursos se luzca con trabajos ajenos, o se venda como original lo que se ha copiado o traslúcido. Se ha hecho en el Consejo indicaciones para la consecución de estos objetos en lo posible, i discutidas que sean, se elevaran a la consideración del Gobierno.

Lo dicho hasta aquí se aplica especialmente al Instituto Nacional; pero debo añadir que es también mui satisfactorio el estado presente de la Academia Militar, i del Seminario Conciliar de Santiago; que, sobre todo, la disciplina interior del primero es digna de particulares elojios, i presenta (puede decirse sin exajeracion) un modelo perfecto: que en él se ha dado por la primera vez a la jimnastica el lugar que le corresponde; que hai ajena al establecimiento una excelente escuela de cabos; que en el Seminario es cada día mejor i más extensa la enseñanza; i que en algunos de los Colejios provinciales costeados por la Nación se observan también, aunque en diferentes proporciones, mejoras i adelantamientos. El de _La Serena es el que ocupa el grado más alto en la escala; especialmente por el cultivo extenso de algunos ramos de ciencias físicas, que tienen relación con la industria minera. Síguenle de cerca los de Talca i Cauquenes; i si el de Concepción ha tenido que luchar contra el defectuoso plan de estudios que allí se observaba, el Señor Vice-Patrono nos da la esperanza de que concluido, como va a serlo pronto, el espacioso edificio que se le está construyendo, se organizará el internado i se mejorará la enseñanza. Este progreso de los establecimientos que paga la Nación, ha influido favorablemente en los colejios de los particulares; i no ha tenido poca parte en él la necesidad de conformarlos, en todo lo sustancial, a los textos i programas del Instituto, donde deben ser examinados i aprobados los alumnos para que les sirvan sus estudios en las carreras profesionales.

Este privilegio de recibir exámenes que habiliten para los grados universitarios, no se ha conferido a la Academia Militar i Seminario, sino respecto de los alumnos que se educan en esos establecimientos, se ha extendido el mismo privilegio, con algunas restricciones adicionales, a los colejios de la Serena, San Felipe, Cauquenes i Talca; que sin esta medida sería difícil prosperaran, porque la ventaja de recibir exámenes valedores para grados universitarios de que goza el Instituto de Santiago, atrae 
demasiada la juventud de las provincias de la capital. El Consejo de la Universidad está convencido de que el privilejio del Instituto, que es una carga pesadísima para sus profesores, debe sin embargo mantenerse con el menor número de excepciones posible; porque mientras se rindan allí los exámenes con la solemnidad i rigor que conviene, ejercerá el Instituto, como sucede actualmente, una influencia benéfica sobre los otros planteles de educación; se propagaran a estos los progresos i mejoras de aquel; i sin recurrir providencias directas, se obtendrá en la enseñanza toda la uniformidad que es de desear.

La instrucción colejial i superior del Instituto comprende de los siguientes: catecismo, historia sagrada, i funciones de la lei, sucesivamente; gramática castellana, lengua castellana, latinidad, lengua griega, que cuenta todavía con pocos alumnos, francés, inglés, dibujo natural i de paisaje (además del dibujo lineal, que se enseña a los jóvenes artesanos), aritmética, aljebra i jeometria para los estudiantes de humanidades, jeografia i cosmografía, principios jenerales de literatura, literatura latina, nociones de historia de la literatura, cursos bastante complejos de historia profana, filosofía, derecho natural, economía política, teoría de la lejislacion, derecho romano i patrio, derecho económico, derecho de jentes, todos los ramos de matemáticas puras hasta la jeometria sublime i jeometria descriptiva, topografía i geodesia, física experimental, química aplicada a la mineralojita i la medicina, botánica aplicada a la medicina, anatomía fisolojia, patolojia i clínica. Varios de estos ramos se enseñan en cursos bienales, i para los de gramática castellana, latinidad, historia, i matemática hai bastante número de clases.

En la Academia Militar se enseñan, además de la relijion, la gramática i métrica castellana, el francés i el inglés alternativamente, aritmética, aljebra i jeometria, incluyendo algunos de los ramos superiores, jeografia i cosmografía. En la sección de cabos ajena al establecimiento, fuera de los competentes conocimientos relijiosos se dan lecciones de aritmética, jeometría, i gramática castellana. En una i tras sección ocupan el debido lugar la escritura, el dibujo, la ordenanza, el ejercicio militar i la táctica, la urbanidad i la jimnástica.

Finalmente, el Seminario Conciliar de Santiago comprende clases de gramática castellana, latinidad, francés, retórica, jeografia, filosofía, fundamentos de la fe, elementos de aritmética, aljebra i jeometria, de botánica jeolita i zoolojia, canto llano, teolojia, dogmatica, e historia eclesiástica.

Estos son los tipos de educación colejial i superior, de educación militar i eclesiástica, a que procuran aproximarse los establecimientos de las provincias, aunque en diferentes grados, como he tenido el honor de indicaros. Se hacen esfuerzos para extender progresivamente la planta de unos i otros, cuanto lo permitan sus fondos, que en algunas partes son demasiados escasos. 
La separación de las dos enseñanzas preparatorias i superior, decretada por el Supremo Gobierno, i próxima ya a realizarse, es una medida que deberá producir los mejores efectos en una i otra, i que dará el necesario desenvolvimiento al Cuerpo Universitario, ocupándolo directamente en la segunda. Este es un ministerio esencial de las universidades. Pero la nuestra no es una mera copia de las antiguas corporaciones que tienen este título en las naciones europeas. La primera idea de su creación está en nuestra carta fundamental, que exije la institución de una elevada magistratura, a cuyo cargo corra la inspección de la enseñanza nacional, i su dirección, bajo la autoridad de Gobierno. Esta superintendencia es la que la lei ha depositado en el Consejo Universitario; i sea que resida en una autoridad unipersonal, o como ha parecido más conveniente, en una autoridad colejiada, es evidente que pudiera existir sin la Universidad. Pero la lei orgánica ha querido reunir a la superintendencia de la educación nacional sin cuerpo, que dividido en cinco secciones, dedique su atención no solo a la enseñanza, sino al cultivo de los diferentes estudios, comprendiendo hasta la instrucción primaria. - La separación de que acabo de hablaros tiene por objeto hacer efectivo el primero de estos deberes, la enseñanza. La Universidad va a ser así un cuerpo docente; i según las provisiones del Decreto Supremo, va a serlo de un modo que, a mi juicio, concilia dos grandes miras, la de dirijir la enseñanza en el sentido de la moralidad i la utilidad pública, i la de dejar a los profesores universitarios la independencia i libertad que corresponden a su alta misión.

Pero no se debe olvidar que nuestra lei orgánica, inspirada, en mi humilde opinión, por las más sabias i liberales ideas, ha encargado a la Universidad, no solo la enseñanza, sino el cultivo de la literatura i las ciencias; ha querido que fuese a un tiempo Universidad i Academia; que contribuyese por su parte al aumento i desarrollo de los conocimientos científicos; que no fuese un instrumento pasivo, destinado exclusivamente a la trasmisión de los conocimientos adquiridos en naciones más adelantadas, sino que trabajase, como los institutos literarios de otros pueblos civilizados, en aumentar el caudal común. Este propósito aparece a cada paso en la lei orgánica, i hace honor al Gobierno i la Lejislatura que la dictaron. ¿Hai en él algo de presuntuoso, de inoportuno, de superior a nuestras fuerzas, como han supuesto algunos? ¿Estaremos condenados todavía a repetir servilmente las lecciones de la ciencia europea, sin atrevernos a discutirlas, a ilustrarlas con aplicaciones locales, a darles una estampa de nacionalidad? Si así lo hiciésemos, seríamos infieles al espíritu de esa misma ciencia europea, i la tributaríamos un culto supersticioso que ella misma condena. Ella misma nos prescribe el examen, la observación atenta i prolija, la discusión libre, la convicción concienzuda. Es cierto que hai ramos en que debemos, por ahora, limitarnos a oírla, a darle un voto de confianza, i en que nuestros entendimientos por falta de medios no puede hacer otra cosa que admitir 
los resultados de la experiencia i estudios ajenos. Pero no sucede así en todos los ramos de literatura i ciencia. Los hai que exijen investigaciones locales. La historia chilena por ejemplo, ¿Dónde podrá escribirse mejor que en Chile? ¿No nos toca a nosotros la tarea a lo menos de recoger materiales, compulsarlos i acrisolarlos? I lo que se ha hecho hasta ahora en este solo ramo, bajo los auspicios de la Universidad, las memorias históricas que cada año se le presentan (g), lo que se ha trabajado por un distinguido miembro de la Universidad en la historia de la Iglesia Chilena (h) lo que ha dado a luz otro distinguido miembro sobre la historia de la constitución chilena, (i) ¿no nos hacen ya divisar todo lo que puede i debe esperarse de nosotros en un estadio peculiarmente nuestro? Pocas ciencias hai que para enseñarse de un modo conveniente no necesiten adaptarse a nosotros, a nuestra naturaleza física, a nuestras circunstancias sociales. ¿Buscaremos la higiene i patolojia del hombre chileno en los libros europeos, i no estudiaremos hasta qué punto es modificada la organización del cuerpo humano por los accidentes del clima de Chile i de las costumbres chilenas? ¿I un estudio tan necesario podrá hacerse en otra parte que en Chile? Para la medicina está abierto en Chile un vasto campo de exploración, casi intacto hasta ahora, pero que mui presto va a dejar de serlo, $i$ en cuyo cultivo se interesan profundamente la educación física, la salud, la vida, la policía sanitaria i el incremento de la población.

Se han empezado a estudiar en nuestros colegios la Historia Natural, la Física, la química. Por lo que toca a la primera de estas ciencias, que es casi de puras observación a un para adquirir las primeras nociones se trata de ver, no las especies de que nos hablan los textos europeos, sino las especies chilenas, el árbol que crece en nuestros bosques, la flor que se desenvuelve en nuestros valles i laderas, la disposición i distribución de los minerales en este suelo que pisamos i en la cordillera ajigantada que lo amuralla, los animales que viven en nuestros montes, en nuestros campos i ríos, i en la mar que baña nuestras costas. Así los textos mismos de historia natural, es preciso, para que sirva a la enseñanza de Chile, que se modifiquen, i que la modificación se haga aquí mismo por observadores inteligentes. I dado este paso, suministrada la instrucción conveniente, ¿no daremos otro más, enriqueciendo la ciencia con el conocimiento de nuevos seres i nuevos fenómenos, los catálogos de especies, ilustrando, rectificando las noticias del saber extranjero, recojidas por la mayor parte en viajes hechos a la lijera? El mundo antiguo desea en esta parte la colaboración del nuevo; i no solo al desea; la provoca i la exije. ¿Cuánto no han hecho ya en esta línea los anglo-americanos? Aun en las provincias españolas de América i bajo el yugo colonial, se han dado ejemplos de esta importante colaboración; el nombre del granadino Caldas, que jamás visitó la Europa; i el de Molina, que adquirió en Chile los conocimientos a que debió su reputación, figuras borrosamente en listas de los observadores que han aumentado 
i enriquecido la ciencia. ¿No seremos nosotros capaces de hacer en el siglo XIX lo que hizo en el XVI el jesuita español José de Acosta, cuya historia natural i moral de las Indias, fruto de sus observaciones personales, es consultada todavía por el naturalista europeo? I si lo somos ¿se condenará como inoportuna la existencia de un cuerpo que promueva i dirija este cultivo de la ciencias? Lo dicho se aplica a la mineralojia, a la jeolojia, a la teoría de los meteoros, a la teoría del calor, a la teoría del magnetismo; la base de todos estos estudios es la observación, la observación local, la observación de todos los días, la observación de los ajencias naturales en todas las estaciones sobre todo la superficie del globo. La ciencia europea nos pide datos; ¿no tendremos si quiera bastante zelo i aplicación para recuperarlos? ¿No harán las Repúblicas americanas en el progreso jeneral las ciencias más papel, no tendrá más parte en la mancomunidad de los trabajos el entendimiento humano, que las tribus africanas o las islas de la Oceanía? Yo pudiera extender mucho más estas consideraciones, i darles nueva fuerza aplicándolas a las políticas al hombre moral, a la poesía, i a todo jenero de composición literaria, porque o es falso que la literatura es el reflejo de la vida de un pueblo, o es preciso admitir que cada pueblo de los que no están sumidos en la barbarie es llamado a reflejarse en una literatura propia, i a estampar en ella sus formas. Pero creo que hasta lo dicho para que se forme idea de que el dolor cargo que la lei orgánica impone a la Universidad no es una concepción monstruosa ni prematura, i que podemos i debemos trabajar en ambos con utilidad nuestra i con utilidad común de las ciencias.

La Facultad de Humanidades, que ha empezado temprano a distinguirse entre las otras de la Universidad, lo ha comprendido así. La Facultad de Medicina, la de ciencias Físicas, entran con ardor en esa carrera. El Gobierno para facilitársela, ha aumentado recientemente el número demasiado escaso, de los individuos de que se componen. Los miembros corresponsales, nombrados a propuesta de una $\mathrm{i}$ otra i del Consejo, concurrirán a sus trabajos, haciendo observaciones i recojiendo datos en las provincias i aun en los países extranjeros. Las dos Facultades tendrán reuniones frecuentes, como las tiene la de Humanidades, a quien se debe la alabanza de haber dado el primer ejemplo; serán admitidos en esas reuniones los alumnos que lo deseen; i los resultados que se obtengan, resultados que mirarán principalmente a objetos locales, se pondrán en noticia del público.

Vuelvo, señores, a la enseñanza, que la indisputablemente es el primero de los encargos cometidos a la Universidad, i al mismo tiempo me propongo recordaros lo que se ha hecho relativamente el cultivo, que no están insignificante como algunos piensan. Me ha facilitado con vosotros por las mejoras que se notan en la instrucción preparatoria i científicas; i no es grato decir que en este punto la primera, la principal parte, se debe a las luces, la contracción, el zelo de los excelentes profesores del Instituto Nacional; porque todo lo que es esto se adelanta, se adquiere para los 
demás establecimientos literarios de la República, a los cuales sirve de tipo. Otro asunto se me ofrece, más ingrato, odioso tal vez. Tengo que indicar defectos i vacíos. No corro el peligro de herir ninguna susceptibilidad delicada, porque mis reparos no miran a ningún establecimiento, a ninguna clase particular, a ningún individuo. Son jóvenes i reconozco excepciones honrosas. Temo solo que se me acuse de que deseo sembrar de espinas las carreras profesionales, e imponer condiciones demasiado onerosas a los grados universitarios, exjiendo nuevos estadios $i$ amplitud a los que hoy se hacen. Pero yo cumpliría igual con los derrabes que me impone la lei, si no os diese una cuenta menuda de mis convicciones sobre el estado actual de la enseñanza, sobre la calidad de los frutos que prohíbe, i sobre los medios de perfeccionarla.

En el resto de la Historia i los Fundamentos de la República no tengo nada que notar. El Consejo ha dispuesto que forme una parte de la instrucción preparatoria i científica, exijiendo previo examen i aprobación en él para obtener los grados universitarios. Un miembro de la Facultad de Teolojia bien conocido por sus luces i su dedicación a la enseñanza, ha dado a luz un tratado elemental de la Verdadera Relijion i de la Verdadera Iglesia, a que la aceptación de la autoridad competente i la acojida del público, han hecho completa justicia. Otro miembro de la misma Facultad (j) ha compuesto un curso de historia Sagrada, que hasta ahora solo conozco por el favorable informe de la Comisión respectiva, i que ha sido aceptado para la enseñanza. Es probable que no tardará en publicarse.

Tampoco tengo nada que notar en la Aritmética i Jeografia. Se ha compuesto por un Miembro de la Facultad de Humanidades (k) un tratado de Aritmética Comercial, en que el autor se ha propuesto agotar todas las $(, \ldots)$ del cálculo a los problemas que puedan ofrecerse en las operaciones mercantiles; pero no habiendo evacuado todavía su informe la Comisión nombrada al efecto, no debo anticipar mi juicio. El tratado de Jeografia (l) que se prefiere generalmente en los colejios, tiene entre otros métodos el de estar adaptado para los establecimientos de Chile. Un profesor del Instituto Nacional (1l) ha dado a luz un buen resumen del Cosmografía; i recientemente se ha publicado por un miembro de la Facultad de Humanidades un tratado extenso, en que se ha procurado dar una descripción entera del sistema del Universo, según el estado presente de la ciencia astronómica; si con algún suceso, no me toca decirlo.

En cuanto al estadio del idioma nativo no encuentro que sea suficiente; porque no veo que el resultado corresponda al gran número de clases destinadas a él. Las hai en todos los colejios i en algunos más de una; las hai no pocas escuelas; i sin embargo, juzgando por el uso jeneral i por las producciones de nuestra prensa, se echa de ver que es limitadísimo el número de los que escriben el castellano con mediana pureza; i digo más, el número de los que no incurren en faltas graves, 
que argüirían una ignorancia grosera o la más vulgar educación, si no viésemos muchas veces en los mismos escritos que se deslucen con ellas, nuestras evidentes de escojidas instrucción, i extensa cultura intelectual. Discursos se pronuncian, i en reuniones literarias, salpicados de solecismos chocantes. Es preciso confesar que bajo este punto de vista la literatura chilena no está a la altura de la de otras Repúblicas Americanas. Pero no basta indiar el mal; es preciso señalar las causas. Yo encuentro una en la superficialidad de los libros que sirve de textos, que no hacen notar los vicios en que generalmente se incurre; que no advierten aquellos que no se pegan de la lectura de obras extranjeras i en especial francesas; que limitándose a nociones vagas i estériles, no dan bastante noticia de las especialidades del castellano. Otro encuentro en el poco uso que se hace de composiciones escritas de estilo familiar, y en la falta de preceptores idóneos. Encuentro la principal de todas en que no se lee los clásicos de la lengua, que se miran con excesivo desdén cabalmente cuando son más estudiados i admirados que nunca en las naciones cultas de Europa. Veo con gusto que en el Instituto Nacional se ha dado de algunos años a esta parte más amplitud i profundidad a este estudio, i que uno u otro establecimiento particular ha seguido su ejemplo. Pero en las escuelas es donde yo desearía principalmente que se adoptasen otro método, haciendo conocer a los niños las faltas que en el lenguaje popular se comente (que aunque graves, no son muchas), en vez de cargar su memoria i ofuscar su entendimiento con definiciones inexactas, que no representan los hechos de la lengua, i que realmente no dicen nada a la inteligencia del niño. No es dar un buen cimiento a la disciplina mental, acostumbrar el entendimiento a pagarse de palabras que no le representan ideas.

Encuentro, generalmente hablando, algunos defectos en el estudio que se hace de la lengua latina. Veo que no se atiende bastante a su pronunciación. Nimio parecerá este reparo. Pero si no se nos hace habitual la prosodia latina, i si no se empieza a formar ese hábito desde mui temprano, es decir, desde que empiezan a proferirse las primeras palabras latinas, i nos acostumbramos a enunciaciones viciosas i acentos falsos, ¿no desaparecerá para nuestros oídos aquella harmonía, que todavía no es dable percibir en el metro latino? Yo encuentro, además, en lo poco que se fija la atención sobre esta materia una de las causas que contribuyen a la incorrección con que habían i escriben la lengua patria aun personas de no vulgar cultura que han estudiado el latín. - Veo que no se dan a conocer, sino mui por encima, las jenialidades i elegancias de esta bella lengua, que aun medianamente poseída, facilita de un modo increíble el aprendizaje de las otras, i sirve de guía para el recto uso de nuestro propio idioma, hablado i escrito. - Veo que la práctica antigua de composiciones escritas ha caído en desuetud, i me felicito de que un eminente i profesor francés $(\mathrm{m})$ se haya propuesto renovarla, facilitándola con el excelente libro, que ya ha dado a la luz, i con el que debe seguirle, que completara 
la materia. Aprovecho esta oportunidad de manifestar mi gratitud a los auxilios que me ha prestado este distinguido literato en otros trabajos de la misma especie, $i$ lamento que no haya logrado hasta ahora, a pesar de liberal patrocinio de nuestro Gobierno, difundir en la juventud de Santiago la afición a la lengua griega, tan importante en el estudio de la literatura profana i de las ciencias eclesiásticas.

En el Instituto Nacional se hace actualmente el estudio del latín de un modo, que no dudo satisfará en breve a todas las exigencias razonables. Quizás es allá solo donde se ha comprendido que debe aspirarse a algo más que una tintura superficial, suficiente apenas para el eclesiástico, el jurisco santo i el médico. Yo he visto muestras brillantes en los exámenes del último año escolar; i entre los alumnos que han completado esta parte de su educación, los leí de un mérito sobresaliente, que ejercen el profesorado en el mismo Instituto i en otros establecimientos. El discurso provocado por uno de ellos $(\mathrm{u})$ sobre esta misma materia en un acto solemne del Instituto Nacional, es una producción admirable por el talento, por el lenguaje i en el joven profesor una afición entusiasta a la lengua literaria que recomienda. Indicar la superioridad de los textos de que se hace uso en el Instituto, i que se adopta gradualmente en otros colejios, sería de mi parte un testimonio recusable. Pero no puedo dejar de hacer una observación. En el movimiento del espíritu humano, todo marcha, aun el conocimiento de los idiomas antiguos, en que la materia parecía estar agotada. ¿Quién imajinaria que hasta en el mecanismo de la declinación de los nombres i pronombres, hubiese algo nuevo que decir? Pues aun en esta parte, la concienzuda i laboriosa Alemania, compulsando prolijamente todos los monumentos de la antigüedad latina, ha denunciado notables inexactitudes en las reglas i tipos comunes. Los textos en que no están consignadas estas revelaciones de la filolojia moderna, son por consiguiente defectuosos.

El estudio de las lenguas vivas extranjeras se perfecciona de día en día. Solo sería de desear que, como el del castellano i el latín, se completasen con algunas nociones de las respectivas literaturas. En la preparación a la carrera comercial o a los usos generales de la vida, este complemento podría parecer un lujo superfluo; pero no debe decirse lo mismo de los estabelecimientos que cuentan la literatura entre los ramos de enseñanza, i sobre todo del que debe presentar a los otros un modelo tan cabal i perfecto como nuestras circunstancias permitan. No pediría yo, por supuesto, un estudio profundo. A lecturas escojidas, traducciones de los mejores países, explicaciones de los principios estéticos, i comparaciones de los varios gustos i estilos en las principales épocas literarias, desempeñado todo esto en las lecciones orales por profesores competentes i con alguna más detención en la literatura antigua i la de nuestra lengua, debería limitarse este curso, que daría, a mi juicio, un brillante realce a la educación del hombre de letras, del eclesiástico i del jurisconsulto. Prefieres generalmente lo más moderno en las lecturas i las obras 
francesas de nuestros días son exclusivamente el tipo de los escritores noveles. Así es que se ven demasía las veces, al lado de la incorrección i la inexperiencia, disculpables en la literatura que ensaya sus primeros vuelos, el magisterio, la presunción, que es característica de una literatura de saciedad i refinamiento. Se me figura una hermosa joven, descalza i desgreñada, i al mismo tiempo cubierta de afietes i de andrajos brillantes. La clase de literatura superior, que entra ahora en el plan de los estudios universitarios, será probablemente un medio eficaz de poner dique a esta especie de culteranismo, que afortunadamente ha empezado ya a excitar la nausea de nuestra juventud más instruida.

En la historia se ha tomado una dirección acertada. Se buscan los hechos, i se dejan los sistemas para los estudios privados. Mas aquí, como en otras partes, se echan menos libros elementales adecuados. Sabido es que la crítica i la filosofía han dado en estos últimos años una forma enteramente nueva a ciertas partes de la historia, a la de los primeros siglos de Roma, por ejemplo. I con todo eso, los que debieran exhibirnos, aunque en punto motor, el estado actual de la ciencia histórica, son todavía por la mayor parte, lo que eran un siglo hace, se da a los niños el carácter de hechos auténticos, i se juzgan e (...) las revoluciones.

Otro defecto, relativamente a nosotros. No se crea que para dar este estudio entre nosotros la forma que le conviene, podemos servirnos enteramente de obras extranjeras, por excelentes que sean, como las hai sin duda. Podemos i debemos aprovecharnos de ellas, pero con ciertas modificaciones, acomodadas a nuestros antecedentes $\mathrm{i}$ a nuestras circunstancias actuales. Tómese el mejor texto elemental de historia y moderna que se haya escrito en francés; i notaremos que dándose en él, como es natural, dimensiones colosales a la Francia, se presenta en una escala mucho más reducida la (...), cuya historia en casi su totalidad es la nuestra; la América española apenas se columbra de paso, a lo lejos, i quizás no ocurre una sola vez el nombre de Chile. Nada digo de otros graves inconvenientes, en lo que concierne a la relijión i al orden público. No creo, pues, que se culpe de nimio al que desee que, elejido un buen texto, se adapte, se supriman ciertas partes, se corrijan otras, se introduzcan algunas, i se varíen las proporciones de los objetos, acomodando la perspectiva, por decirlo así, a nuestro punto de vista; trabajo sin duda más difícil que lucido: pero necesario. Esta es una de las miras a que me parece que debe atenderse en la revisión de programas i textos, recomendaciones a las Facultades y al Consejo.

La Historia de Chile es para nosotros demasiado importante para no merecer un curso especial. Las memorias históricas que piden anualmente la lei orgánica, i los otros trabajos parciales que han empezado a publicarse, i que forman hasta ahora los más apreciables frutos demuestro cultivo literario, facilitaron la redacción de un texto nuevo, exacto i completo. La historia de Chile es una materia a que consagra actualmente su atención la Facultad de Humanidades, acreedora bajo 
tantos respectos al reconocimiento nacional. Ocupase desde luego en recoger los documentos manuscritos, que se han salvado de los estragos del tiempo, o más bien, de la incuria; se propone transcribirlos, compilarlos, analizarlos; promover la impresión de todo lo que parezca de algún interés, i reproducir las obras impresas que están a punto de desaparecer para siempre, i que merezcan conservarse.

Entre los trabajos históricos relativos a Chile, no debo pasar en silencio el más notable por su extensión i originalidad de cuantos se han acometido hasta ahora. Ya concebís, señores, que aludo a la historia Eclesiástica de nuestro país, en que se ha ocupado por algunos años el digno Decano de la Facultad de Teolojía (o) i a cuya última parte ha sido adjudicado uno de los premios de este año, como lo fue a la primera uno de los del año anterior. Yo no conozco la obra sino por el informe de la Comisión; pero el juicio i saber de los respetables eclesiásticos que lo han emitido, me inspira la mayor confianza. Me son mui conocidos, además, no solo la ilustración i laboriosidad del autor, sino su zelosa solicitud en la investigación i adquisiciones de materiales, sin perdonar molestia ni costo. Entiendo que entre los documentos que ha podido acopiar, los hai bastantes curiosos, relativos a la historia jeneral de Chile. Creo que nuestra historia eclesiástica, publicada por la prensa, no tardará mucho en satisfacer la impaciencia con que se desea;

El vuelo que en tan pocos años han tomado los estudios históricos hace esperar que lleguemos en esta línea a un grado de adelantamiento que satisfaga a los más descontentadizos.

Pero el objeto más interesante de todos en este departamento es la jeografia chilena. El primer trabajo importante en ella, después de los pintorescos bosquejos publicados en los diarios chilenos por don Claudio Gay, ha sido la Araucaria del Sr. Domeyko; interesante bajo el punto de vista jeolojico, no menos que bajo el moral i político por la animada pintura de las costumbres araucanas, i por la discusión filosófica de un problema vital para Chile: el de la civilización de aquella raza indómita.

Aguardamos con ansia la parte relativa a la jeografia en el Viaje Científico de don Claudio Gay, que la ha hecho un objeto especial de investigación. No puedo menos de lamentar aquí los obstáculos que han retardado la ejecución de una obra, tan importante para nuestra historia natural i civil, i para el conocimiento de nuestro propio país, bajo todos los aspectos. Por muchos títulos debiera ser ella buscada, leída, meditada por los lectores chilenos: los documentos inéditos que contiene son del mayor interés. No se pueden alabar demasiado el zelo i diljencia que su autor ha empleado para recojerlos en este país, i en los demás que ha visitado. Cuanto puede hacer una inteligencia superior unida a la más paciente laboriosidad, lo ha hecho el instruido viajero, hijo adoptivo de Chile, para dar su obra toda la copia de noticias 
curiosas i de descripciones orijinales, que ha sido posible, i para hacerla digna de la protección que le ha dispensado el Gobierno, i le ha prometido el público.

Otro viaje científico está ya a punto de emprenderse, con el objeto de explorar la jeolojia de Chile, de estudiar su jeografia i de hacer a su agricultura indicaciones útiles.

Llevadas a cabo estas dos empresas, i continuando con el zelo que ahora se hace, los trabajos históricos, conoceremos nuestro suelo, nuestra naturaleza física, nuestros antecedentes i no iremos a mendigar esta instrucción en obras extranjeras, excelentes, admirables bajo otros aspectos pero plagadas de errores en casi todo lo que concierte a nosotros.

La clase superior de literatura, que como he dicho, entra ahora en el plan de los estudios universitarios, pondrá este ramo en el pie conveniente. Se echará una ojeada rápida pero instructiva, sobre las diversas literaturas, contemplándolas en las obras i pasajes más generalmente admirados, i consultando (cuanto sea posible) los orijinales. No se trata de dar pábulo a aquella falsa erudición, que consiste en adoptar juicios ajenos i opiniones sistemáticas sin conocer los objetos sobre que recaen. Un compendio de la historia de la literatura hará el complemento de los estudios de este ramo.

La filosofía no es la ciencia que se ha cultivado menos en Chile. Se han estudiado i juzgado con acierto sus varios sistemas. Un antiguo profesor del Instituto Nacional (p) cuyo alejamiento del resto de sus méritos trabajos, es tan justamente llorando, abrió el camino al estudio de examine i convicción propia, que es eminentemente esencial i característico de la filosofía. Otro excelente profesor, miembro de la Facultad (q) ha seguido sus huelas. Su curso tiene el mérito de ser fácilmente accesible a las intelijencias juveniles, i otro que insisto en mirar como indispensable en los textos i como demasiadamente raro, el de la corrección i pureza en el lenguaje. Sé que se preocupa en la relación de un nuevo texto, i no dudo que dará en él la debida importancia a la lojica i a la filosofía moral, la primera obra toda la extensión que merece. Dio una alta importancia a los estudios lojicos, incluyendo en ellos el de raciocinio inductivo, que conviene a las ciencias experimentales, i el de la crítica que pesa los testimonios o interpreta los textos dudosos. Ni llevo ni admiración a lo moderno hasta el punto de mirar con desprecio la herencia de aquel granjero que con tanta sagacidad trazo el camino de la razón en algunos de sus más familiares procedimientos. No me avergüenzo de pensar que la teoría aristotélica del raciocinio merece estudiarse: en esta materia, como en otras, no debe confundirse el uso con el abuso.

Sobre el estudio de las ciencias matemáticas i físicas poco añadiré a lo que he dicho en otra parte de este discurso. Pero no sería justo pasar por alto los grandes servicios que ha prestado en este ramo un antiguo i benemérito profesor que es 
hoy Decano de la Facultad, i que los ha coronado con su traducción del tratado de Jeometria Descriptiva de Leroy ( $\mathrm{r}$ ). Faltaría también a la justicia si no consignase aquí los servicios de un eminente Profesor francés (s) que fundó las clases de química i mineralojia en el Instituto, i cuyos Elementos de química mineral sirven actualmente de texto. Merecen también distinguida mención los del Secretario de la Facultad Don Ignacio Domeyko, que después de haber establecido las clases de química, física i mineralojia en la Serena, con sus respectivos laboratorio i gabinete, continúa los cursos de M. Crosnier en el Instituto Nacional, ha abierto uno de física; ha publicado un Tratando de Ensayos, elementos de mineralojia, una breve exposición de la jeolojia de Chile, el ya citado viaje a las provincias australes de Chile con el título de Araucanía, un trabajo sobre las Aguas de las inmediaciones de Santiago; i de actualmente una nueva edición de la Física de Poillet en castellano, para la enseñanza de este ramo. Todos conocen sin duda su introducción al estudio de las Ciencias naturales, elocuente reseña de las maravillas de la naturaleza i de las prodijiosas conquistas del injenio humano; himno sublime, inspirado a la par por el sentimiento relijioso, i por entusiasmo de la ciencia.

Poseedor este ramo de una excelente colección de instrumentos, proporcionada por el Supremo Gobierno, sería de desear que, pues se hacen observaciones meterolojicas, se publican diaria o periódicamente, como se hace en otros países, no más adelantados que Chile ¿I no estaremos en estado de aprovecharnos de los vastos trabajos astronómicos de Europa, si quiera para que no adolezcan nuestro almanaque de las imperfecciones i vacios que en él se notan? El objeto parecerá pequeño; ¿pero de qué se trata para desempeñarlo, sino de reducciones fáciles que trasportan al horizonte de Santiago algunos de los fenómenos celestes que tan exaltada i copiosamente i con tanta anticipación se anuncia en París i Londres?

Se necesita imperiosamente un local adecuado para nuestro Museo de Historia Natural, colección preciosa, a que dio la primera planta i mucha parte de lo que contiene (recordémoslo con gratitud) el ilustrado viajero de quien ya he tenido el honor de hablaros.

Otra necesidad es la de buenos textos de Historia Natural, adaptados a nuestro suelo. He indicado el inconveniente de los destinados a la enseñanza de esta ciencia en Europa; i para remediarlo nada es mas a propósito que el Viaje Científico del mismo Sr. Gay. Este es un trabajo a que nos parece llamado el estimable Profesor de botánica i química médica, en el Instituto, que lo es también de ciencias naturales en el Seminario de Santiago: uno de los primeros individuos que en Chile han dirijido su atención a esta parte interesante de los conocimientos humanos $(\mathrm{t})$.

Pero el vacío que más, urje llenar es el que ha señalado el Sr. Vice-Patrono. Su señoría lamenta lo reducido de las aplicaciones que se han hecho hasta ahora de los estudios matemáticos. Carecemos, dice, de arquitectos civiles, de ingenieros 
expertos con la construcción de caminos, puentes i toda clase de obras públicas. Pero el mismo Señor ministro nos da esperanzas halagueñas de ver remediada esta necesidad dentro de poco tiempo. El Gobierno, añade Su Señoría, ha aceptado con entusiasmo las ideas de fundar en Santiago una escuela práctica de arquitectura civil, bajo la dirección de un ingeniero que debe llegar de Europa de un momento a otro. El Gobierno ha preparado también todo lo concerniente a la organización de un verdadero cuerpo de ingenieros de minas i de ensayadores.

El ramo de medicina es, según entiendo, de lo que se desenvuelven i perfeccionan cada día. En esta parte se debe todo a la solicitud del Supremo Gobierno; i si Chile puede ya gloriarse de tener facultativos instruidos i de merecida reputación, formados en nuestras aulas, obra es del constante fomento i patrocinio que la autoridad suprema ha dispensado a este ramo. Conocido es el zelo del Sr. Decano de la Facultad, que ha formado, poco tiempo hace, el plan de estudios para la escuela de Medicina; i que en el Consejo de la Universidad es uno de los que más esforzadamente abogan por el rigor i severidad de los estudios no este, como en los otros departamentos de la enseñanza

Arriba indique las reuniones periódicas de la Facultad que inmediatamente van abrirse, $\mathrm{i}$ el nombramiento que se ha hecho de nuevos miembros de número, i corresponsales, para tacitarlas, i dar principio a los demás trabajos. Me linsejeo pues de que veremos pronto realizarse aquella importante prescripción de la lei: "Además del fomento jeneral de todos los ramos de este departamento científico, dedicara la Facultad una atención especial al estudio de las enfermedades endémicas de Chile, i de las epidémicas que flijen más frecuentemente la población de las ciudades i campos del territorio chileno; dando a conocer los mejores medios preservativos i curativos, i dirijiendo sus observaciones a la mejora de la higiene pública i doméstica".

En el ramo de ciencias legales i morales hai un decidido progreso. Pero no creo que debamos limitar nuestra ambición a lo que y se ha hecho. Esto es de todos los ramos de ciencias humanas el más importante para nosotros ¿Qué falta, pues, se preguntará, para que sea su estudio lo que debe ser? Voi a indicarlo, sometiendo, como en todo, mi juicio al de mi ilustrado auditorio.

Yo desearía, señores, que el estudio de la jurisprudencia romana fuese algo más extenso i profundo. Lo miro como fundamental. Para alcanzar su fin no basta que se aprenda la nomenclatura de la ciencia, i que se adquiera una tintura de reglas i prescripciones inaplicables muchas ves a nuestra práctica. El objeto de que se trata es la formación del jurisconsulto científico; el aprendizaje de aquella lojica especial, tan necesaria para la interpretación i aplicación de las leyes, i que forma el carácter que distingue eminentemente la jurisprudencia de las romanos. Para hacerlo es preciso poner al alumno en estado de consultar las fuentes; i el método histórico es el que nos las hace accesibles. Yo abusaría de vuestra paciencia, si tratase de 
recomendar este método con autoridades de los jurisconsultos unas eminentes de nuestros días. Ni creo tampoco que sea menester refutar la preocupación de aquellos que desconocen la utilidad práctica del derecho romano, sobre todo en países cuya lejislación vivir es una emanación i casi una copia de la romana. Basta decir que en ninguna época ha sido más altamente apreciado, ni más generalmente recomendado su estudio, aun bajo el punto de vista de la práctica judicial i forense. Yo citare con Savgny, el ejemplo de los jurisconsultos franceses, que se sirven dice, del derecho romano con mucha habilidad, para ilustrar i completar su código civil, logrando así según el verdadero espíritu de ese mismo código.

Yo deduzco de estas observaciones la necesidad de dar algún ensanche al estudio del Derecho Romano, por medio de un texto más comprensivo i sustancial. El que sirve ahora es demasiado mezquino i pobre, i la instrucción que suministra no es comparable a la que se daba en nuestros mismos establecimientos literarios cuarenta o cincuenta años ya. La formación de un nuevo texto, en que se dé a la materia la amplitud que reclama, aprovechándose para ello de lo mucho i excelente que se ha publicado en la Memoria i la Francia en estos últimos años es una obra a que la Facultad de leyes se ha creido llamada i que en ya se trabaja. No urje menos la redacción de un texto del derecho privado patrio, es decir, del español con todas las adiciones i correcciones que ha recibido en Chile desde nuestra emancipación política, que no son pocas, ni de poca importancia. El método histórico es aquí absolutamente necesario para dar a una masa tan heterogénea la debida unidad i harmonia. Cada elemento nuevo introducido en un cuerpo legal afecta más o menos directamente los elementos anteriores, $i$ su influencia se extienden a veces mucho más de lo que a primera vista parece, sin que por eso de de exagerarse otras veces. Una obra como la que indico, no debe ser una simple yustaposicion de lo nuevo a lo antiguo. Ella supone, según yo lo concibo, una elaboración científica, que traza la dirección i alcance de cada una de las diversas partes injeridas en el cuerpo legal, i formula lo que resulte de la acción combina la de todas. No es una reforma lo que se le pide, sino una exposición luminosa, a que concurran, sin dejarse ver demasiado, la erudición legal i aquella lojica particular de que ha tenido el honor de hablaros, i que insisto en mirar como la prenda más apreciable del verdadero jurisconsulto, a nuestro derecho público, en que comprendo el constitucional i el administrativo en sus varios ramos de gobernación, hacienda i justicia, debe darse también el debido lugar en los estudios legales, por medio de un tratado elemental elaborado de la misma manera que el de lejislacion civil. Mucho es pues lo que resta que trabajar en este ramo para poner los estudios en el pie conveniente. O no deben desanimarnos las dificultades, en vista de lo que se ha hecho i se está haciendo en un departamento de la ciencia legal, que no es por cierto el menos vasto i difícil. Las instituciones de derecho Canónico Americano, recientemente dadas a la luz por el Rev. Obispo 
electo de Ancud, son una obra que, si se me permite expresar un juicio, llena completamente mis ideas en cuanto a la formación de textos elementales, su titulo mismo está diciendo que es un libro destinado a las naciones hispano-americanas; pero lo está además especialmente a la iglesia i de Chile. No está reducido a las dimensiones de un libro estrictamente elemental. El profesor que lo use, tendrá a su arbitrio elegir las materias de indispensable conocimiento para la totalidad de los alumnos, mientras que el resto puede servir a los de superior aplicación i talento para extender sus estudios i al profesor mismo para refrescar los suyos i consultar en caso necesario las fuentes, que se acotan siempre con el debido esmero. El estilo es carísimo, generalmente puro, i tiene toda la elegancia que puede pedirse a un texto de enseñanza. Libros de doctrina igualmente selecta i copiosa, que no salga de los límites de la instrucción elemental sino para darle más luz i solidez, adaptaros a la América, adaptados a Chile, es lo que o desearía que estuviésemos en todos los ramos de enseñanza primaria, preparatoria i superior. Este es un objeto que ocupa la atención del Consejo Universitario i en que se trabaja actualmente.

La economía política, que forma parte de los estudios de derecho y lejislacion, es uno de los ramos en que se echa menos no libro o propósito para la enseñanza i adaptado a Chile, ¿quien no percibe cuán importante, cuan indispensable es que en un texto de esta ciencia se tenga a la vista el país con sus peculiares necesidades i recursos? La estadística, creada, fomentada por el Supremo Gobierno, puede ya suministrar una buena copia de datos preciosos, que según lo ha indicado, a lo que yo recuerdo el Sr. Rector del Instituto, en su último discurso público, debiera formar una parte de la instrucción que se da en este ramo. Si se adopta para ella alguna de las muchas obras elementales que se han publicado i se publican en Europa, convendría que por lo menos se le agregase un apéndice, que fuese como un corolario de la teoría jeneral, aplicado en Chile.

Para la lejislacion jeneral no hai un texto completo, uno de sus más importantes tratados es la materia de un libro que sirve actualmente para la enseñanza. Se han suscitado contra él objeciones graves, sobre cuyo mérito no me es lícito anticipar el juicio del individuo nombrado para examinarlo, que es uno de los que más honran a la Universidad por sus luces i de los que con más zelo le sirven, a pesar de sus incesantes tareas profesionales (u). El autor de este libro (x) ha ejercido con mucho lucimiento el profesorado, es uno de nuestros más aventajados escritores, i uno también de los miembros del cuerpo de quienes hai más que esperar por su talento, su laboriosidad i su amor al saber.

La Academia de práctica forense prospera. No puedo menos de mencionar con satisfacción los informes que en estos últimos meses han dado más de una vez el digno Decano de la Facultad sobre el brillante desempeño de los jóvenes que se han presentado para obtener el grado de licenciado. 
Desarrollado como ha tenido el honor de indicarlo, el estudio de las ciencias legales, se hace preciso extender a tres años el que ahora se hace del derecho civil, romano o patrio i creo que es fácil hacer esta innovación, sin que para ello sea menester aumentar el total del tiempo que se dedica al aprendizaje de la profesión forense; porque se logra el objeto de diferir la enseñanza de algunos ramos superiores para el bien que media entre los grados de bachiller i licenciado, época mui a propósito para hacerlos con más detención i aprovechamiento.

Las ciencias sagradas prosan. El manual del párroco americano, otra producción del reverendo Prelado electo, de quien ya os he hablado, i otro libro, también no solo de completa i escojida doctrina, según el dictamen de personas inteligentes, sino de adaptación al país, merece mencionarse en primera línea, por la inmensa importancia del asunto, i lo grave de la necesidad que está destinado a satisfacer. La academia de Ciencias Sagradas; crea la organizada por el Mui Rev. Prelado que tan dignamente preside hoy a la iglesia chilena, debe mucho a la contracción i zelo de su benemérito sucesor en el Decanato de la Facultad. Finalmente, en el Seminario Conciliar de esta diócesis se han extendido i mejorado los estudios, como lo manifiesta la lista de los cursos que en él se siguen actualmente, pero siento decir que los otros establecimientos de la misma especie se hallan todavía en embrión i tienen absolutamente que hacer para ponerse en el pie conveniente. Entre las circunstancias que han contribuido generalmente a la mejora de la instrucción, o no sería justo que pasase en silencio los servicios del actual Rector del Instituto: he tenido frecuentes ocasiones de apreciar sus luces, su actividad vigilante i zelosa.

Un agüero feliz para el porvenir es la noble i santa emulación con que las casas reljiosoas de la Capital se han presentado a concurrir a la grande obra de la enseñanza nacional. De tiempo atrás había dado el primer señalado ejemplo los relijiosos de estricta observancia de la Orden de Predicadores, cuyo zelo i liberalidad en este punto son dignos de todo elojio. Animados del mismo espíritu se presentan ahora el convenio principal de la misma orden i de relijioso Mercenarios. El Sr. Decano de Teolojia, formó el plan de estudios para estas casas, que ha sido revisado por el Consejo i ha merecido la aprobación del Supremo Gobierno. Ni son de olvidar los servicios que ellas prestan al mismo tiempo a la instrucción primaria. Solo es de desear que se propague el mismo zelo a las otras de la capital i a los convenios de las provincias, que es donde más se hace sentir la necesidad de esta cooperación; pero no comprendo aquí a Valparaíso, donde una orden venerable que ha colocado la educación entre los primeros objetos de su instituto.

tiene para cada sexo un establecimiento floreciente, como en la capital uno de niñas, a que es de esperar, como he dicho, que se añada otro de niños en Santiago.

He indicado de paso algunos de los trabajos del Consejo. Daros un catálogo individual de todos ellos, ni es posible en esta ocasión ni necesario. Bastará 
indicaros las materias en que generalmente se ocupa. No hai estado de escuela o de colejio, fiscal o municipal, o particular (i si bien no se reciben todos los que la lei prescribe, se reciben muchísimos) que no sea examinado por el consejo, que hace las observaciones debidas sobre las faltas que nota, que tramite al Supremo gobierno la noticia de las necesidades que se sufren en los establecimientos fiscales o municipales, i estimula el zelo de las Juntas, Inspectores i Perceptores. El consejo revisa los textos i programas; promueve su formación, discute menudamente los reglamentos i planes de estudios; inspecciona directamente por medio de sus miembros los colejios de la Capital; i da impulso, en cuanto le es posible, a los objetos de las facultades. No hai corporación alguna en que la asistencia sea más asidua, ni a que concurra constantemente mayor número de sus vocales. I en este 'punto debo decir que no son inferiores a los otros miembros los Consiliarios (x), que no reciben por ello retribución alguna.

Recientemente ha determinado el Consejo que una parte del pequeño sobrante de las sumas asignadas para gastos de las secretarias se invierta en suscripciones a las más acreditadas obras periódicas que sobre materias científicas y literarias no publican en Europa i en Los Estados Unidos de América. Estas obras se destinan al uso de las Facultades i de la juventud estudiosa.

Finalmente, se ha representado al Supremo Gobierno, que entre varias lijeras modificaciones a la lei orgánica, proponga a la Legislatura añadir al Consejo otro consiliario más, i que lo sea siempre, por razón de su empleo, el Rector del Instituto Nacional. El cuidado que tiene el Gobierno de elegir para este difícil cargo personas idóneas, como lo han sido las que lo han ejercido por una larga serie de años, i el conocimiento experimental que en él se adquiere de los defectos o necesidades de la enseñanza, hacen, a mi juicio mui conveniente la participación de este empleado en las medidas del consejo i no podrá menos de facilitarlas. Lo mismo digo relativamente al delegado universitario, cuando se haya nombrado.

Solo me resta, Señores, cumplir con el último de los deberes que en esta ocasión me impone la lei, pagar un tributo de respeto a la memoria de los miembros fallecidos en este quinquenio, que se han distinguido por su zelo a favor de la instrucción, yo coloco en primer lugar aquel hombre insigne, en cuya pérdida he llorado la Patria la de muchos hombres, sabio legislador, que presidió a la formación de nuestro código constitucional; ministro diplomático, que representó con zelo i dignidad a la República en Inglaterra i en el Perú; ilustrado ministro de Justicia, que trabajó con acierto en la reforma de la administración judicial i dejó preparado un vasto proyecto para la organización de este ramo: defensor enerjico de los intereses nacionales i de las leyes en el ejericio del ministerio público, en el Senado i en el Consejo de Estado; esforzado promovedor de la instrucción pública en el Consejo Universitario, en la Facultad de Leyes de que fue el primer Decano, en la 
Academia de práctica forense, i que en todos estos destinos hizo resplander, a la par sus intelijencias luminosa, enriquecida con extensos i variados conocimientos, atesorados en una memoria privilejiada, un alma pura, a quien asustaba hasta la más lejana sombra de miras opuestas a la escrupulosa integridad del hombre público, de lo que yo pudiera citar prueba conocidas de pocos, conocidas de uno de mis colegas que está presente i gozo de sus más íntimas confianzas; una independencia de carácter, que no se doblega jamás a influjos personales, que no traicionó jamás a sus convicciones, que jamás se arredro de expresarlas, un culto al honor nacional que rayaba en lo caballeresco, aquel rarísimo patriotismo que busca el bien sin mendigar la popularidad, todo esto sostenido adornado por una elocuencia de razón, fácil, fluida, animada, espontánea, llena de rasgos felices, sin la menor apariencia de estudio. De sus cualidades sociales i domésticas ¿Qué puedo decir que no sea sabido de los que me escuchan? ¿Quién ignora cuan elevado, con profundo, fue en Don Mariano Egaña el sentimiento relijioso? Esposo i padre tierno, i no menos tierno hijo, que llevaba el amor a la memoria de su venerable padre hasta la idolatría, amigo fiel, consecuente, servicial, liberal bienhechor de la humanidad doliente $i$ de la pobreza desvalida, alma afectuosa, i enerjica i sin embargo al crimen, a la prevaricación, a las contemplaciones indebidas, a la perniciosa induljencia. Yo no temo que se me culpe de exajeracion, cuando digo que la naturaleza no presenta sino de tarde en tarde un conjunto tan espléndido de virtudes i talentos. I aun no le he dicho todo aun no os he hablado de aquella amabilidad de trato, que en medio de su desprecio, tal vez excesivo, a las exterioridades frívolas que la sociedad impone como deberes i cuya misión es la que menos perdona, daba tanta gracia a su conversación i la hacía tan instructiva, tan interesante, i tan exenta de pedantería, ni de aquella franqueza jenia, que trasparentaba todos los movimientos de su alma, ni de aquellos nombre hospitalidad de su casa de campo, asilo de recreación inocente, monumento de amor filial, adorado con esmero i gusto y a no pequeña costa, todavía la más bella residencia campestre en Chile, i uno de los primeros objetos de curiosidad del viajero que visita la capital. Construyéndome a lo que tiene relación con la Universidad i la instrucción pública, D. Mariano Egaña tomo siempre una parte principal en los trabajos del Consejo Universitario asistió con la mayor asiduidad a sus reuniones, fue el alma de sus deliberaciones i propendió en el con especial zelo a la difusión de la enseñanza religiosa i moral. Sabido es que hizo un estudio particular de la historia i antigüedad chilenas: ha dejado una colección de documentos curiosos que las ilustran i apuntes históricos de su pluma. Formó una rica biblioteca, en que no se ha olvidado ningún ramo de ciencia o de literatura o en que no faltan obras de las que por su precio no están a el alcance de muchos, no pocas de ellas únicas en el país, raras algunas en la misma Europa copias sobre todo en historia i jurisprudencia i lo que a mi juicio la recomienda particularmente, 
adaptada al uso de lectores americanos, de lectores chilenos. Yo que he tenido la ocasión de registrar este opulento depósito me he convencido de que al formulario, se tuvo mui presente a la América Española, i a Chile. Comprado por la Nación que ha querido vincular allí para siempre la memoria de aquel ciudadano ilustre, ornamento de la humanidad i gloria de Chile, estará pronto abierto a la juventud estudiosa i al público. D. Mariano Egaña, vivirá así para la Patria a que fue arrebatado en una época de la vida en que el vigor de las facultades intelectuales la daba todavía la esperanza de largos e importantes servicios.

Aun al lado de este hombre eminente pueden aparecer, sin deslucirse, dos venerables sacerdotes, dignos de recordarse por lo que hicieron a favor de la instrucción pública. El primero es el ilustrísimo Sr. Don José Ignacio Cienfuegos. Decidido, desde que dio Chile el primer grito de libertad, a sostener tan santa causa, trabajo en ella esforzadamente como ciudadano, como miembro del Poder Ejecutivo, como miembro de la Lejislatura, confinado al presidio de Juan Fernández, fue allí el consuelo de sus compañeros de destierro. Después de aquella época de infortunio para las armas de la Patria, se lo nombró Gobernador del Obispado de Santiago i no necesito recordaros el zelo con que en este destino se consagró a la Iglesia Chilena, no menos que a los intereses del Estado, como miembro del Senado Conservador como Diputado de Talca, Cura de aquella ciudad, no contento con ejercer dignísimamente su (...) ministerio, había contribuido, de su propio peculio en gran parte, a la construcción de la iglesia i de una hermosa casa de ejercicios espirituales. Fue prebendado de la Catedral de Santiago, en la cual ascendió hasta la dignidad de (...). En edad ya avanzada, impulsado por el anhelo de promover el bien de la Iglesia chilena, hizo dos viajes a la capital del mundo católico, el primero con el carácter de Ministro Plenipotenciario, en que obtuvo la Santidad de Pío VII, concesiones importantes, i la misión de un Vicario Apostólico provisto de plenísimas facultades para el arreglo de los negocios eclesiásticos. En el segundo, enteramente privado, se le condecoró con la Mitra de Retimo in patribus infidelium, a coptado con la mira de proveer las necesidades de Chile, donde no había a la sazón ningún Pastor de igual jerarquia. Instituido después para la Diócesis de Concepción, desplegó allí con nuevos lustre el espíritu apostólico de que estaba animado. Presentes teneis las inestimables prendas de este benemérito sacerdote: un patriotismo que no se desmintió jamás, una constante dedicación al servicio de la iglesia i del Estado; un zelo virtuoso, templado por la prudencia i la mansedumbre, una ilustración superior; una intachable pureza de conducta, una atractiva suavidad de carácter. En medio de las graves ocupaciones que os he bosquejado, sirvió meritoriamente a la instrucción pública. En 1819 desempeñó a satisfacción de todos los comisionados que se le confirió para el restablecimiento del Instituto Nacional. En 1820 escribió i dio a luz a sus expensas también, el Catecismo de Doctrina 
Cristiana que goza de tan merecida reputación i de que repartió gratuitamente en el país innumerables ejemplares. El célebre abate Molina había puesto a disposición del Señor Cienfuegos, su deudo, una valiosa hacienda situada en la provincia de Maule i el Señor Cienfuegos la cedió a Talca para que se emplease en la educación de la juventud sus productos que forman la principal renta del Colejio de aquella ciudad.

Don José Santiago Iñiguez es el segundo de los individuos del Clero Chileno que creo dignos de memoria como bienhechores de la instrucción pública: sacerdotes venerables, modelo de sencillez, austeridad en la vida privada, lumbrera de la iglesia de Santiago por sus virtudes i por su vasta erudición en las ciencias sagradas. Versado también en las ciencias i la literatura profanas, fue el primer profesor de economía política en el Instituto Nacional, donde enseñó además el Derecho Natural i de Jentes, como Teolojia i Humanidades en el Seminario conciliar. Ejerció con distinción el profesorado, i a pesar de su quebrantada salud concurrió a los trabajos de la Facultad a que pertenecía, Selló sus eminentes servicios a la relijión i la nación destinados su cuantioso patrimonio a objetos de beneficencia pública.

Otro hombre, señores, se asoma a mis labios, que no me es posible pronunciar. Ya concebís que aludo a un joven, que nacido en Inglaterra, se formó principalmente en Chile que casi niño fue profesor de Instituto Nacional, que contribuyó allí bastante al restablecimiento del estudio de la lengua latina, que en una gramática de este idioma introdujo por la primera vez las doctrinas de la filolojia europea de los últimos años. Que dejo acopiado materiales para una segunda edición de aquella obra en que desgraciadamente hubo de trabajar otra mano, que cultivó la literatura con suceso que se distinguió en el foro desde que entro en él, que fue precipitado al sepulcro en la flor de la vida, malogrando la más bellas esperanzas. El vecindario de Santiago le lloró, i conocía solamente la mitad de su alma.

Hai otro asunto i será el último; más personal, si cabe. Reelejido casi unánimemente por este ilustre cuerpo para el primer lugar de la terna del recotrado vacante, reelejido de este modo en la reunión universitaria más numerosa que se ha visto hasta ahora, debo aprovechar de esta primera oportunidad para dar a la Universidad un testimonio público de mi profunda gratitud. Debo darlo así mismo al Exmo. Señor Patrono, que se ha dignado confirmar el sufragio de la Universidad. Debo darlo al Sr. Ministro de Instrucción Pública, que se ha servido mencionar a las Cámaras Lejislativas, mi reelección en términos de honoríficos para mí. Pero la mejor muestra de mi reconocimiento será la consagración de mis débiles fuerzas al servicio de la Nación Chilena, mi constante favorecedora, de la Universidad i de la juventud estudiosa, en quien (lo he dicho muchas veces i me complazco en repetirlo) en que tengo una fe sincera: la Patria, que hace tanto pro ella, que espera tanto de ella, a cuya organización es llamada ella a poner la última mano, no verá 
frustrada su esperanza. Contribuir a este venturoso resultado, es la misión de la universidad en la esfera de sus atribuciones. Para la parte que en esta misión me toque a mí, siento no poder ofreceros más que zelo i trabajo. Contad con ellos, mientras me quede un resto de vida i de fuerzas.

\section{PIE DE PAGINA.}

(a) Según los datos publicados recientemente por el Ministerio de instrucción pública, en vista de las noticias que acaban de referirse por el Señor Intendente de Chiloé, hai en toda la provincia 17 escuelas fiscales, i 67 particulares, educándose en las primeras 952 individuos, $i$ en la segunda 1648; total 3600. Esta hace variar un poco el cálculo de 1 por 17 que he dado en la provincia, juzgando por los cuatro departamentos de Quinchao, Calbuco, Dalcahue, i Chonchi. Computando la población local en 52000 almas (49000, según el censo de 43), resulta que de cada 20 individuos de toda edad i sexo, va uno a la escuela. Chiloé conserva pues una considerable superioridad sobre todas las otras provincias de la República, en cuanto al número de personas que reciben la instrucción primaria. En la provincia de Valparaíso, una población no baja de 80000 almas, sostiene 53 escuelas particulares. En la de Santiago, la población no baja de 230000 almas, más que el cuádruplo de la de Chiloé; i el número de escuelas de particulares no llega al duplo de las de aquella remota provincia, tan escasa de recursos de toda clase. Este resultado, que puede mirarse como "bastante exacto, es altamente honroso al pueblo chilote".

(b) Don Máximo Argüelles.

(c) Por Don Domingo Faustino Sarmiento, autor también del Método gradual de lectura, que la Facultad de Humanidades ha designado como el más a propósito para las escuelas, i de otros opúsculos destinados a la instrucción primaria.

(d) Por Don Rafael Minvielle, Miembro de la Facultad.

(e) Por Don Vicente (...) López, Miembro de la Facultad.

(f) Por Don José Dolores Bustos.

(g) Don José Victorino Lastarria.

(h) Don Antonio García Reyes.

(i) El Sr. Bustos, mencionado anteriormente.

(j) Don Pedro Palazuelos.

(h) Investigaciones sobre la influencia social de la conquista i situación social de los españoles en Chile, por D. José Victorino Lastarria, de la Facultad de Humanidades, año 1844; Memoria sobre las primeras 8...) de la independencia en Chile por D. Diego José Benavente, de la Facultad de Leyes i ciencias políticas en 1843; memoria sobre la primera escuadra nacional por D. Antonio García Reyes, de 
la Facultad de Humanidades año 1816; Memorias sobre el primer gobierno nacional por D. Manuel A. Tocornal, de la Facultad de Leyes año 1847.

(i) no se ve.

(j) El Presbítero Don Francisco de Paula Taforo.

(k) Don Rafael Mivielle.

(l) Por Don José Victorino Lastarria.

(li) Don Carlos Rizo Patron.

(m) no se ve.

(n) no se ve.

(p) D. Ventura Mirin autor de unos elementos de filosofía bien conocidos i que manifiestan profundos conocimientos en esta ciencia.

(q) Don Ramón Briceño.

(r) Son mis conocidos los trabajos anteriores del Sr. Don Andrés Gorbea, su traducción de las Matemáticas Paras de Franceut, de que solo falta el Cálculo integral, retardado por algunas dificultades geográficas, La Jeometria, trigonometría, nociones de jemometria descriptiva i jeometria practica, destinadas a la Escuela Militar de Santiago i adoptadas a nuestra Academia Militar. El Sr. Ballaras había traducido la Aritmética i el A. E.

(s) A. M. Crosnier se debe la construcción del laboratorio en el Instituto.

(t) A Don Vicente Bustillos se deben algunos apreciables trabajos de análisis química, entre ellos una memoria sobre el Acido piroleñoso, presentada a 1 Facultad de que es miembro.

(u) Don Gabriel Copamo, miembro de la Facultad de Leyes.

(x) Don José Victorino Lastarria. 